\title{
What It Means to Be an Adolescent Teacher-And-Peer-Independent Motivation Type
}

\author{
Hannah Marei Krunke ${ }^{1} \&$ Diana Raufelder ${ }^{1}$ \\ ${ }^{1}$ Free University Berlin, Berlin, Germany \\ Correspondence: Diana Raufelder, Habelschwerdter Allee 45, 14195 Berlin, Germany. Tel: 49-030-838-55748. \\ E-mail: diana.raufelder@fu-berlin.de
}

Received: June 9, 2014

doi:10.5539/jel.v3n3p33
Accepted: July 10, $2014 \quad$ Online Published: July 17, 2014

URL: http://dx.doi.org/10.5539/jel.v3n3p33

\begin{abstract}
In order to enhance our understanding of interindividual differences in academic motivation, the present study examined the interplay of personality, psychosocial adjustment and socio-academic factors in a subsample of adolescent students identified as teacher-and-peer-independent motivation type (MT) $\left(N=295 ; \mathrm{M}_{\mathrm{Age}}=13.71\right)$ in Brandenburg, Germany. A latent structural equation model was run in order to test whether psychosocial adjustment mediates the association between personality and socio-academic factors. The results revealed that psychosocial adjustment fully mediates the associations between personality and socio-academic factors. Additionally, results showed that neuroticism is a strong predictor of socio-academic difficulties. The findings could be integral of supporting students on a more individualized level.
\end{abstract}

Keywords: interindividual differences, personality, person-oriented approach, psychosocial adjustment, socio-academic factors, structural equation modeling

\section{Introduction}

\subsection{Interindividual Differences in Students' Academic Motivation Patterns}

Particularly during adolescence, when social relationships become increasingly complex (Bukowski, Simard, Dubois, \& Lopez, 2011) both the teacher-student relationship and the student-student relationship become essential for most students' academic motivation (Wentzel, 2009a, 2009b; Wentzel, Battle, Russell, \& Looney, 2010), which in turn positively or negatively effects their academic achievement (Flanagan, Erath, \& Bierman, 2008; Wentzel, 1998). In order to better understand interindividual differences within students' motivation patterns, the present study adopted a person-oriented perspective (Bergmann, 2001) focusing on students for whom relationships with peers and teachers are not integral to their academic motivation and socio-academic factors. The basic goal in person-oriented research is "to group individuals into categories, with each one containing individuals who are similar to each other and different from individuals in other categories" (Muthén \& Muthén, 2000, p. 882), whereas variable-oriented research tries to explain the associations between variables (for detail see Magnusson, 2003; von Eye \& Bogat, 2006).

\subsection{Preliminary Research}

In preliminary research we examined whether social relationships in school are equally important for academic motivation across a large sample of adolescent students $(N=1088)$. Different motivation types (MTs) were identified due to the way their academic motivation was found to be dependent and/or independent of peers and teachers (Raufelder, Jagenow, Drury, \& Hoferichter, 2013). Overall, socio-motivational dependency exists when the motivation of individuals is affected by other's motivation, learning behavior or perceived support (Hoferichter \& Raufelder, 2014). That means a student's motivation in school context can be predominantly affected by motivation, learning behavior or social support from peers and/or through teachers' motivation and perceived support (Raufelder, Drury, Jagenow, Hoferichter, \& Bukowski, 2013; Wentzel, 2009a, 2009b). Contrary, socio-motivational independence exists when the motivation of individuals is unaffected by other's motivation, learning behavior or perceived support (Hoferichter \& Raufelder, 2014). With this in mind, four different motivation types (MTs) have been identified using confirmatory latent class analysis (CLCA): teacher-dependent MT, peer-dependent MT, teacher-and-peer-dependent MT and teacher-and-peer-independent MT (Raufelder, Jagenow, Drury, \& Hoferichter, 2013). Membership for this 4-class solution was as follows: 
9.5\% teacher-dependent MT (50 girls, 57 boys), 36.5\% peer-dependent MT, (233 girls, 161 boys), 27.8\% teacher-and-peer-dependent MT and (166 girls, 126 boys), and 26.3\% teacher-and-peer-independent MT (138 girls, 157 boys). With regard to interindividual and developmental differences (Wigfield \& Eccles, 2001), the establishment of motivation typologies might help to foster and support each student individually within the school system. Most schools still tend to expect students to learn and behave in uniform ways: students who do not fit this pattern are often viewed as maladjusted instead of considering that they have different motivational needs. Therefore this typology should be used as a gateway to understand interindividual differences in academic motivation. The results of our preliminary research indicated that the teacher-dependent MT, the peer-dependent MT as well as the teacher-and-peer-dependent MT experience social relationships as an important source of academic motivation. In contrast, the academic motivation of the teacher-and-peer-independent MT did not appear to be dependent of social relationships, meaning that for example, teaching style, teacher's awareness of student's progress and abilities, and peer learning behavior are not essential to academic motivation for students of this motivation type. As the traditional educational system is based on learning in classroom settings and strong teacher involvement, students of the teacher-and-peer-independent MT might be disadvantaged in comparison to the other three MTs. Before aiming at identifying effective starting points for supporting these independent students, it is necessary to better understand what it means to be a teacher-and-peer-independent MT.

\subsection{Current Study}

Effects of positive relationships with schoolmates, teachers or both, have been studied extensively (Black \& McCartney, 1997; Roffey, 2012; Wentzel, 1998). Positive influences have been found, for instance enhanced social and academic competence in the school context (Wentzel \& Asher, 1995) as well as an increased achievement and school adjustment (Birch \& Ladd, 1997). The experience of support and care has directly been linked to increased interest in class and school (Wentzel, 1998). But what about students who are neither dependent on peers nor on teachers to be motivated? In particular, academic motivation can be understood as a result of the dynamic interaction between the developing adolescent (personal level characteristics) and his or her school context (contextual level characteristics), defined in Lerner's theory of developmental contextualism (Lerner, 1986, 1998; see also Hamre \& Pianta, 2006; see also Raufelder, Drury, Jagenow, Hoferichter \& Bukowski, 2013). By focusing on specific personal level characteristics within the school context, this study aims to better understand the teacher-and-peer-independent students. On a personal level, aspects of psychosocial adjustment were tested as mediators of the association between specific personality factors and socio-academic factors with the intention of identifying effective starting points from which students of the teacher-and-peer-independent MT might be better supported in an academic context. Therefore, the present study in a first step examined a general relation between personality, psychosocial adjustment and psycho-academic factors. In a second step, three paths were developed to examine the association between three personality factors (extraversion, neuroticism, autonomy) as predictors, three aspects of psychosocial adjustment (social competence, depression, and relatedness) as mediators and three socio-academic factors as outcome variables (problems with peers, emotional problems, and individual school self-concept).

Path 1: Extraversion-Social Competence-Problems with Peers. Social competence can be traced back to Thorndike (1920) who defined it as sensitivity to others and the ability to act wisely in human relations. The ability to behave in a socially skilled manner has been shown to be essential to the development of healthy relationships as well as to successful participation within a community (Cacioppo, 2002). In adolescence, social competence has also been found to be of importance within the academic context (Wentzel, 1991). A deficiency in social skills has been shown to be related to problems with peers, such as low friendship quality and victimization (Caravita, Di Blasio, \& Salmivalli, 2009; Crawford \& Manassis, 2011). While, it has been discussed earlier that positive peer relationships foster academic achievement, problems with peers are related to a decrease in the students' performance (Véronneau, Vitaro, Brendgen, Dishion \& Tremblay, 2010). These outcomes underline the importance of investigating factors, which affect the degree of problems with peers. The researcher expects social competence to be a possible predictor within the present population. Interestingly, different researchers (e.g., Schneider, Ackerman \& Kanfer, 1996) have linked social competence to personality traits, which may also help to explain individual differences in the degree of experienced problems with peers. For example, it has been shown that extraversion is positively linked to social skills (Guerin et al., 2011; Schneider et al., 1996) and negatively linked to problems with peers (Mynard \& Joseph, 1997). Similarly, the personality trait of neuroticism might function as a predictor of psychosocial adjustment and socio-academic outcomes. 
Path 2: Neuroticism-Depression-Emotional Problems. While depression in children and adolescents was neglected in the past, dismissed as nonexistent or equated to depression in adults, out of necessity youth depression has more recently become a more significant, expanded focus of attention. The empirical literature is still limited and inconsistent, however, the prevalence of depression among children and adolescents is estimated to be about $10-20 \%$ (Petermann, 2005). Depressive children and adolescents are strikingly unhappy, rarely enjoy themselves, have few interests and can be short-tempered. There are multiple factors, which have a significant impact on the development of youth depression. The effects of peer relationships have been found to be a mediator as well as a moderator in relation to youth depression (Epkins \& Heckler, 2011). Over time, youth depression has been found to have an impact within the academic context (Boulard, Quertemont, Gauthier, \& Born, 2012) not least through its association with emotional problems (Comer, 2010; Essau, 2007; Hazell, 2002), such as worry, unhappiness, clinginess, and fear (Goodman, Lamping, \& Ploubidis, 2010). Many researchers (e.g., Brown \& Rosellini, 2011; Jylha \& Isometsa, 2006) have linked high levels of neuroticism to an increased risk for depression. As such, highly neurotic students are expected to be at risk for depression.

Path 3: Autonomy-Relatedness-School Self-Concept. In comparison to the other three MTs, the independent MT was found to be socio-motivational independent (no dependency on peers and teachers as motivators) and consequently more autonomous in their academic motivation and learning behavior (Raufelder, Jagenow, Drury, \& Hoferichter, 2013). Autonomous learning behavior is key to students' academic engagement (Hafen et al., 2012) and motivation (Eccles et al., 1993). However, autonomy is only one half of the story. In 1966 Kagitçibasi introduced the "autonomous-relational self", which was defined as a "healthy synthesis of the two basic human needs for agency and relatedness" (p. 180). Kagitçibasi's work is very much in line with Deci and Ryan's (1985) "self-determination theory" which also names autonomy and relatedness as two basic needs inherent in human motivation. Wehmeyer and Schalock (2001) found participants who behaved very self-determined also to be highly autonomous. Furthermore, Kupfer (1982) suggested autonomy to be related to self-determination but also to be an essential determinant for the self-concept. More recently, highly self-determined participants were found to have more favorable self-concepts than those who scored low on self-determination (Valkenburg \& Peter, 2008; Wehmeyer \& Schalock, 2001). Furthermore, Guay, Ratelle, Roy and Litalien (2009) specified autonomous motivation in greater detail and found it related to the school self-concept. This study aims to create a more precise picture of the school self-concept.

Empirically, autonomy (Lynch, La Guardia, \& Ryan, 2009) as well as social relatedness (Decovic \& Meeus, 1997) were both found to be essential determinants of a healthy self-concept, including academic self-concept.

\subsection{Research Aims and Hypotheses}

Based on the theoretical and the empirical background outlined above, the current study examines the following two hypotheses:

Hypothesis 1: Association between personality, psychosocial and socio-academic factors. In general, we hypothesized that there is an association between personality, psychosocial and socio-academic factors.

Hypothesis 2: The mediating role of psychosocial factors in the association between personality and socio-academic factors. Following the idea of a more individual-centered view of the teacher-and-peer-independent MT, the principal aim of the current study was to create a model based on personality factors, social adjustment and socio-academic outcomes in order to better understand what it means to be a teacher-and-peer-independent MT. We hypothesized: (1) that social competence would mediate the association between extraversion and problems with peers, (2) that depression would mediate the association between neuroticism and emotional problems, and (3) that relatedness would mediate the association between autonomy and school self-concept (see Figure 1).

\section{Method}

\subsection{Participants}

A subsample of $2957^{\text {th }}$ and $8^{\text {th }}$ grade students $\left(\right.$ male $=53.2 \%$, female $\left.=46.8 \% ; M_{\text {age }}=13.71\right)$ from a larger sample $\left(N=1088 ; M_{\text {age }}=13.70 ; S D=0.53\right)$ in secondary schools in Brandenburg, Germany, were selected due to the identification as teacher-and-peer-independent motivation type in the above-mentioned preliminary research (Raufelder, Jagenow, Drury, \& Hoferichter, 2013). Ethnicity data was not collected due to the very low percentage of ethnic minorities in Brandenburg (2.6\%). Unfortunately, because of laws in Germany that prohibit asking a first party for information about a second party (e.g., asking students about the income of their parents), information about socio-economic status was not available. Out of a pool of 124 secondary schools in Brandenburg, the 23 participating schools were selected randomly. 


\subsection{Procedure}

Permission was successfully sought from the Department of Education, Youth and Sports of Brandenburg to conduct this study. Subsequently, parental permission was obtained. The data collections were carried out on two regular class days and were conducted in the classroom setting. One session lasted 90 minutes. The data was collected in summer and fall 2011, which is the beginning of the German school year. The researchers and teachers remained in the classroom. Students were given detailed instructions about the procedure and questionnaires, with particular attention given to an explanation of the Likert-scale. All participants of the sample $(N=1088)$ were asked to complete a questionnaire package consisting of several scales measuring different aspects of academic achievement such as peer- and teacher-based motivation, personality factors and psychosocial adjustment. The students were told that their participation was voluntary and that they were not obliged to respond to any of the questions. Furthermore, the students were permitted to ask questions. Confidentiality was ensured.

\subsection{Measures}

All measures used in this study are well-established instruments developed for German adolescents, which psychometrics (validity and reliability) has been proved several times.

Personality. Personality traits were measured using the personality inventory Five Factor Personality Inventory for Youth (FFPI-J) (Szirmák, 2005), which is an adapted version of the FFPI for use with young informants and consists of 5 subscales. In the present study we used the following three subscales: neuroticism that consisted of 3 items: e.g., "I feel desperate", $(\alpha=.71)$, extraversion that consisted of 3 items: e.g., "I like to chat" $(\alpha=.70)$, and autonomy that consisted of 2 items: e.g., "I know what I want" $(\alpha=.70)$.

Psychosocial Adjustment. Psychosocial Adjustment was measured via three established scales: (1) The Interpersonal Competence Questionnaire (ICQ) - German version (Riemann \& Allgöwer, 1993). The scale is made up of 15 items (e.g., "I can easily be a sensitive listener for a saddened friend of mine") indicated good reliability $(\alpha=.83)$. (2) Depression. A German version (Gräfe et al., 2004) of the Personal Health Questionnaire Depression Scale (PHQ-9) developed by Kroenke, Spitzer and Williams (2001) was used to assess students' feelings of depression. 8 items such as "How often during the past 2 weeks were you bothered by feeling down, depressed, or hopeless" were rated on a 5-point Likert scale $(1=$ "not at all" to $5=$ "nearly every day") $(\alpha=.84)$. (3) Relatedness. Based on self-determination theory (SDT) (Deci \& Ryan, 1985) relatedness was measured via five items developed by Prenzel, Kristen, Dengler, Ettle and Beer (1996) (e.g., "During class, I feel supported and understood by my classmates" $(\alpha=.87)$.

Socio-Academic Factors. Socio-academic factors were measured with two well-established scales: (1) Goodman's "Strength and Difficulties Questionnaire" (SDQ) (1997). Two subscales were utilized in the present study: problems with peers, which consists of five items (e.g. "I am often teased and bullied by others", $\alpha=.70$ ), and emotional problems, which consists of five items (e.g., "I worry a lot", $\alpha=.72$ ). (2) The Individual School Self-concept scale (SESSKO: Skalen zur Erfassung des schulischen Selbstkonzepts [Schöne, Dickhäuser, Spinath \& Stiensmeier-Pelster, 2002]) consists of six questions. This self-report measure taps students' perceptions of their abilities and intelligence during the school year (e.g., "learning new things at school is ...", possible answers ranging from (1) "more difficult for me now than before" to (5) "much easier for me now than before"). The scale showed excellent reliability $(\alpha=.90)$.

\subsection{Statistical Analyses}

Correlations. Using SPSS (version 21), we conducted bivariate correlations between all variables: personality, psychosocial adjustment and socio-academic factors.

Structural Equation Modeling. Data were analyzed with Mplus version 7.0 (Muthén \& Muthén, 1998-2012) by applying maximum likelihood estimation in order to assess the strength of direct pathways from personality to psychosocial adjustment as well as from psychosocial adjustment to socio-academic outcomes. Furthermore, by using bootstrap analyses we tested whether psychosocial adjustment functions as a mediator of the association between personality and socio-academic factors. We conducted a bootstrap analysis to assess the effects of the mediators by constructing confidence intervals (CI) around the estimates (Preacher \& Hayes, 2008; MacKinnon, 2008). For small sample sizes that may not fulfill assumptions of normality, this nonparametric re-sampling approach is recommended (Preacher \& Hayes, 2008).

We used Mplus (version 7) for the estimation of the model fit. More precisely, we considered four primary fit indices as recommended by Hu and Bentler (1999) i.e., Chi-Square Test of Model Fit $\left(\chi^{2}\right)$, Root Mean Square 
Error of Approximation (RMSEA), Comparative Fit Index (CFI), and Standardized Root Mean Square Residuals (SRMR). To account for missing data models were estimated with full information maximum likelihood (FIML).

\section{Results}

\subsection{Bivariate Correlations}

The results of the bivariate correlations between the variables of interest are reported in Table 1. Overall the results indicate the relevance of the three hypothesized paths.

Table 1. Means, standard deviations, range and intercorrelations between the variables of personality, psychosocial adjustment and socio-academic factors for the teacher-and-peer-independent motivation type (MT)

\begin{tabular}{|c|c|c|c|c|c|c|c|c|c|c|c|}
\hline Variables & 2 & 3 & 4 & 5 & 6 & 7 & 8 & 9 & Range & $\mathrm{M}$ & SD \\
\hline 1. Extra & $.345 * *$ & -.090 & $.234 * *$ & .081 & $.259 * *$ & -0.20 & $.306^{* *}$ & .046 & $1-5$ & 3.14 & .68 \\
\hline 2. SC & & $-.258 * *$ & .052 & -.022 & .083 & $.173^{* *}$ & $.312^{* *}$ & .096 & $1-4$ & 2.78 & .03 \\
\hline 3. PwP & & & $.248 * *$ & $.314^{* *}$ & $.310 * *$ & $-.135^{*}$ & $-.428 * *$ & $-.202 * *$ & $1-3$ & 1.53 & .02 \\
\hline 4. Neuro & & & & $.507 * *$ & $.578^{* *}$ & $-.288 * *$ & $-.128^{*}$ & $-.287 * *$ & $1-5$ & 2.32 & .72 \\
\hline 5. Depres & & & & & $.537 * *$ & $-.128^{*}$ & $-.331 * *$ & $-.298 * *$ & $1-5$ & 2.11 & .06 \\
\hline 6. EP & & & & & & $-.216^{* *}$ & $-.207 * *$ & $-.273 * *$ & $1-3$ & 1.53 & .03 \\
\hline 7. Auto & & & & & & & $.146^{*}$ & $.230 * *$ & $1-5$ & 3.39 & .57 \\
\hline 8. Rel & & & & & & & & $.279 * *$ & $1-6$ & 4.26 & .06 \\
\hline 9. SSC & & & & & & & & & $1-5$ & 3.17 & .05 \\
\hline
\end{tabular}

Note. All measures are standardized. Extra $=$ Extraversion; $\mathrm{SC}=$ Social Competence; $\mathrm{PwP}=$ Problems with Peers; Neuro $=$ Neuroticism; Depres $=$ Depression; EP $=$ Emotional Problems; Auto $=$ Autonomy; Rel $=$ Relatedness; $\mathrm{SSC}=$ School Self-Concept $; * \mathrm{p}<.001 * \mathrm{p}<.05$

\subsection{Structural Equation Modeling}

Before conducting SEM, confirmatory factor analyses (CFA) were run to evaluate which combination of items was most suitable for the models. In favor of an economic model, the number of items was reduced, such as lowand/or cross-loading items $(\alpha<.45)$ were excluded from our analysis. Finally, every latent variable consisted of minimum three items with the exception of the two-item measure relevance of autonomy.

In order to analyze the above-mentioned results of the correlation matrix in more detail, two structural equation models were constructed: (1) a baseline model (full mediation) consisting of direct and indirect paths from personality traits to socio-academic factors through psychosocial adjustment and (2) a less restrictive model (partial mediation) in which direct pathways between personality and socio-academic factors were added. The results of the analysis showed an acceptable fit for the baseline model $\left(\chi^{2}(277)=489.32, p<.001, R M S E A=.05\right.$, $C F I=.91, S R M R=.07)$ as well as for the less restrictive model $\left(\chi^{2}(274)=482.73, p<.001 ; C F I=.91, R M S E A\right.$ $=.05 ; S R M R=.07)$. A chi-square difference test between the (1) baseline model and the (2) less restrictive model did not reach level of significance $\left(\chi^{2}(3)=6.59, p=.08\right)$, which means that the more restrictive model (baseline) was a better fit to the data (see Figure 1). Hence, the test revealed that the association between personality and socio-academic factors was fully mediated by social competence, depression and relatedness (psychosocial adjustment). 


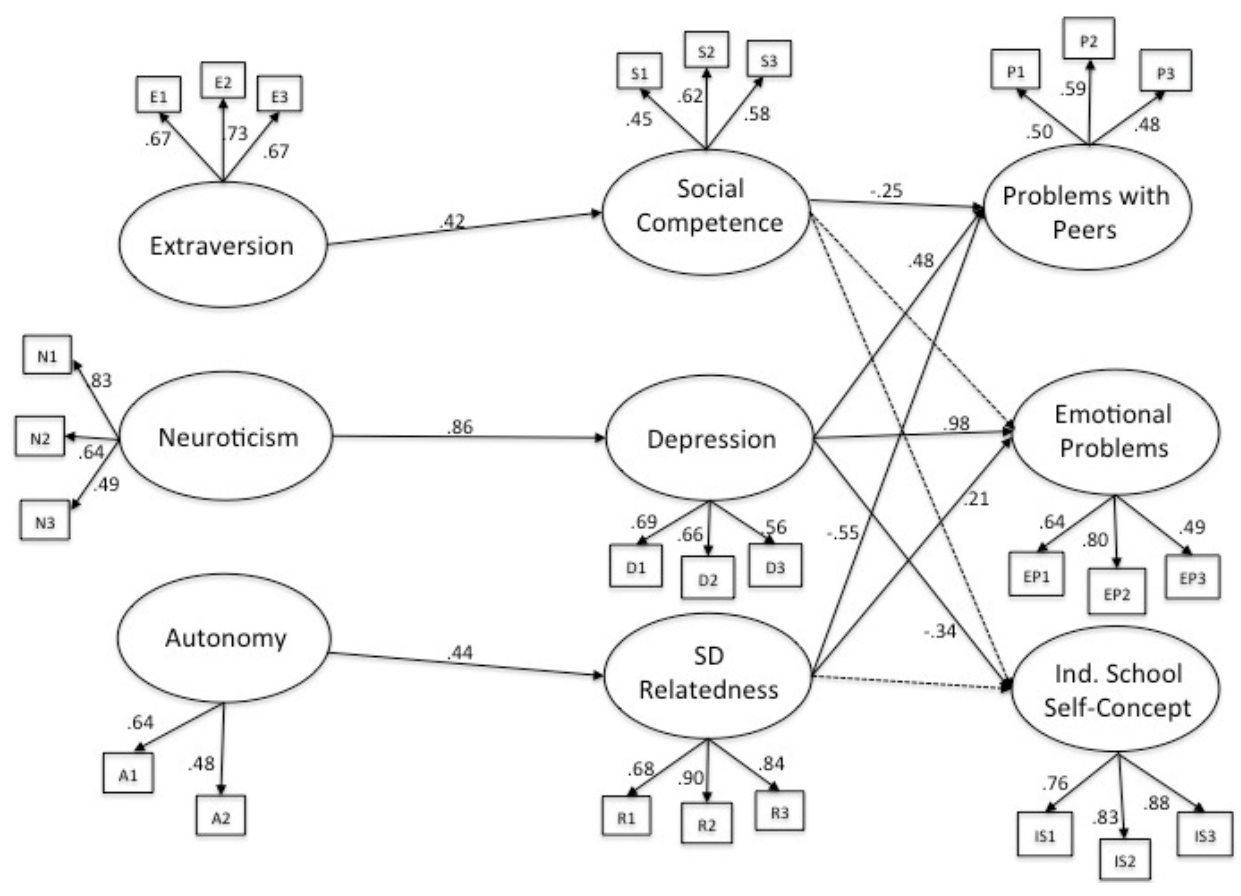

Figure 1. SEM model for personality, social adjustment and socio-academic factors for the teacher-and-peer-independent motivation type

Note. Significant effects shown as standardized coefficients (betas), continuous pathways are significant at $p$ $<.05$; dotted pathways are not significant.

Direct Paths. Based on the hypothesized paths the baseline model of full mediation included (a) three direct effects of personality on social adjustment and (b) nine direct effects of social adjustment (social competence, depression, relatedness) on the different socio-academic factors (problems with peers, emotional problems, individual school self-concept) (see Figure 1), as well as nine indirect effects. The first direct path from extraversion to social competence was found to be significant $(B=.19, \beta=.42, S E=.05, p<.001)$ as well as the second path from neuroticism to depression $(B=.90, \beta=.86, S E=.10, p<.001)$, and the third path from autonomy to relatedness $(B=.70, \beta=.44, S E=.18, p<.001)$. Six direct paths between social adjustment and socio-academic factors were found to be significant: the direct effect from social competence on problems with peers $(B=-.25, \beta=-.55, S E=-.55, p=.03)$, as well as the direct effect from depression on problems with peers $(B=.17, \beta=.48, S E=.05, p<.001)$ and the direct effect from relatedness on problems with peers $(B=-.18, \beta=$ $-.55, S E=.04, p<.001)$. Additionally, the paths from depression to emotional problems $(B=.46, \beta=.98, S E$ $=.10, p<.001)$ and from relatedness to emotional problems $(B=.09, \beta=.21, S E=.04, p=.03)$ were found to be significant. Furthermore, the path from depression to individual school self-concept was found to be significant $(B=-.32, \beta=-.34, S E=.08, p<.001)$. In contrast, the other three paths between social adjustment and socio-academic factors were not significant.

Indirect Paths. The first indirect path from extraversion to problems with peers through social competence was found to be significant $(B=-.05, \beta=-.10, S E=.03,95 \% C I=[-.13,-.01])$. The second path from neuroticism to emotional problems through depression was shown to be significant $(B=.42, \beta=.85, S E=.06,95 \% C I=$ $[.30, .54])$. In contrast, the third path from autonomy to individual school self concept through relatedness was found to be not significant $(B=-.01, \beta=-.01, S E=.08,95 \% C I=[-.16, .16])$. But additionally, the path from neuroticism to problems with peers through depression $(B=.16, \beta=.42, S E=.04,95 \% C I=[.10, .23])$, the path from autonomy to problems with peers through relatedness $(B=-.13, \beta=-.24, S E=.07,95 \% C I=[-.31,-.04])$, and the path from autonomy to emotional problems through relatedness $(B=.07, \beta=.09, S E=.07,95 \% C I=$ $[.00, .25])$ as well as the path from neuroticism to individual school self-concept through depression $(B=-.29, \beta$ $=-.29, S E=.09,95 \% C I=[-.48,-.12])$ were found to be significant. The final model of full mediation explained $11 \%$ of the variance of individual school self-concept $\left(R^{2}=.110\right), 82 \%$ of the variance of emotional problems $\left(R^{2}=.821\right)$ and $92 \%$ of the variance of problems with peers $\left(R^{2}=.915\right)$. 


\section{Discussion}

The main goal of this study was to use a person-oriented approach in order to expand our knowledge of the teacher-and-peer-independent motivation type. Therefore, we examined three hypothesized paths: 1) social competence as mediator of the association between extraversion and problems with peers; 2) depression as mediator of the association between neuroticism and emotional problems and 3) relatedness as mediator of the association between autonomy and school self-concept.

In line with our first hypothesis, the results of the bivariate correlations underlined the strong interactions between personality, psychosocial adjustment and socio-academic outcomes. Particularly, both neuroticism and depression were strongly negatively correlated with autonomy, relatedness and individual school self-concept and strongly positively correlated with problems with peers and emotional problems. In other words, the more students of the teacher-and-peer-independent MT are neurotic, the more they tend to suffer from depression, problems with peers and emotional problems and the lower their levels of autonomy, relatedness and school self-concept. On a more positive note, autonomy was positively correlated with social competence, relatedness, and the individual school self-concept. The results concerning extraversion were more ambivalent, such that extraversion was found to be positively correlated with relatedness, but also with neuroticism and emotional problems. These findings suggest that personality traits are not only essential for motivation, as past research has shown (Busato, Prins, Elshout, \& Hamaker, 2000; Komarraju \& Karau, 2005), but also for psychosocial adjustment and socio-academic outcomes.

In line with our second hypothesis, two of the three expected paths were confirmed: The first indirect path from extraversion to problems with peers through social competence was found to be significant, as well as the second path from neuroticism to emotional problems through depression. The third hypothesized pathway was not fully confirmed: while autonomy predicted relatedness, it was not related to the individual school self-concept, and neither was relatedness.

In line with the present findings, different researchers suggested that the degree of social competence is predictive for different aspects of problems with peers, such as victimization (Caravita et al., 2009) or low friendship quality (Crawford \& Manassis, 2011; Rubin et al., 2004). The results of this study provide support for these findings. Deficits in social skills proved to be related to enhanced problems with peers. In line with the findings of Guerin et al. (2011), low degrees in extraversion were shown to predict low social competence. On this note, additional direct and indirect effects revealed further complex and interesting relationships between the variables of interest: Within the present group, social competence fully mediated the relationship between extraversion and problems with peers. Meaning that social competence could be an effective starting point within the school context to support the teacher-and-peer-independent MT. Furthermore, Wentzel (1991) found social competence to be an important predictor of academic success.

The effects of neuroticism were strikingly negative. Besides the hypothesized path, it was also found that students who were highly neurotic and suffered from higher levels of depression were at risk for increased problems with peers and a weaker individual school self-concept. This underscores the importance of the often-reported powerful effects of neuroticism for the present sample in particular and the academic context in general (Laidra, Pullmann, \& Allik, 2007; Swanberg \& Martinsen, 2010; Tyssen et al., 2007). In line with other studies (Brown \& Rosellini, 2011; Jylha \& Isometsa, 2006) the current study confirmed a relationship between neuroticism and depression and contributed an important insight into the role of depression as a predictor of academic difficulties (Fröjd et al., 2008; Valdez, Lambert, \& Ialongo 2011). When considering the less socially motivated and less socially connected independent MT, these results may have particular relevance. Based on Cohen and Wills' (1985) "buffering-hypothesis", we might presume that the negative effects of neuroticism and depression would be less buffered by social relationships in the case of the independent MT.

As the results of our SEM have shown, relatedness combined with autonomy seemed to have complex effects within the hypothesized model: the indirect effect from autonomy to problems with peers through relatedness as well as the indirect path from autonomy to emotional problems through relatedness were found to be significant. In addition, a negative direct effect between relatedness and problems with peers could be identified. These findings are in support of Kagitçibasi (1996) and Deci and Ryan (1985), who described autonomy and relatedness as the basic building blocks of human motivation. Independent students, who were nevertheless socially related, had fewer problems with peers but more emotional problems. That means, in contrast to the "buffering-hypothesis" (Cohen \& Wills, 1985), for these students, relatedness did not provide emotional relief. In other words, independent students who are socially connected get along better with their peers, but at the same time report higher levels of emotional stress. 


\subsection{Strengths, Limitations and Future Directions}

As with all research, the findings of the present study should be interpreted in light of a number of limitations. First, the sample size of the subsample (teacher-and-peer-independent MT) was relatively small, which may have limited the power of some of the analyses. As such, replication of these findings with a larger, more representative sample is needed. Second, all of the measures were self-report, however, accordingly to Chan (2009) negative attitudes towards self-report data have taken on unjustified proportions (see also Spector, 2006). Following Chan's advice we carefully considered and addressed the four main problems associated with self-report data, and consequently feel justified in our choice of methodology. Third, another point of criticism may lie in the investigation of personality within this study. In literature (Butkovic, Brkovic \& Bratko, 2012; Szirmák, 2005) a five-factor model of personality is mainly described. In the present study, just three personality traits have been taken into account. This is due to the fact that the model was mainly directed at the influence of the mediators (social competence, depression, self-determination). Personality was observed as a possible explanation in the variation of the mediators. Based on the results, the effect of personality was put forward. Fourth, the data is cross-sectional which limits assertions about causality and the development of the motivation types over time. Therefore, a longitudinal extension of the current research considering age group and school form differences (elementary, primary and secondary schools) is warranted. At this point it is important to note that the types should not be understood or used as fixed labels, as this inhibits our ability to see a unique individual's whole dynamic potential. Instead, the knowledge about the typology should help teachers, educators, parents and students themselves improve children's learning by understanding and building on their individual motivation type.

Despite these limitations, the present study has provided important insights into the teacher-and-independent MT. In public schools, students and teachers are often faced with stressful conditions (Phillips, 1993). Nowadays students have to deal with pressure to achieve, isolation from parents (Luthar, 2003), being alone, tests, family fighting, feeling of excessive demands (Ryan-Wenger, Sharrer, \& Campbell, 2005) or schoolwork pressures (Hjern, Alfven, \& Gostberg, 2008). Surveying the past 30 years, stressors were found to have increased in contemporary schools (Ryan-Wenger et al., 2005). Recently, school children are increasingly complaining about psychosomatic pain and psychological troubles (e.g., Karvonen, Vikat, \& Rimpela, 2004; Hjern at al., 2008). Obviously, educational demands are changing and progressively becoming more demanding. These influences may be even stronger if social support within the academic context is deficient or missing. Regarding the teacher-and-peer independent MT, it remains questionable in what ways this group generally profits from social buffering within the academic context as suggested in "buffering-hypothesis" (Cohen \& Wills, 1985). Hence, it appears to be of particular importance to get a more detailed perspective on the teacher-and-peer independent MT. In detail, the present study provides valuable knowledge about the interplay between personality, psychosocial adjustment and socio-academic factors for socially independent motivated students. Taken together, these findings provide a clear directive for supporting students on an individual basis by considering their motivation type as well as differences in personality, which has critical effects on psychosocial adjustment and socio-academic outcomes. Currently, new learning techniques, such as personalized learning schedules, learning diaries, and learning journals (Glogger, Schwonke, Holzäpfel, Nückles, \& Renkl, 2012), are more and more common in daily school life, and are in line with our proposal to design more individual-based school and learning environments. Additionally, the essential mediating role of psychosocial adjustment has implications for both school-psychology and classroom practice; if psychologists, educators, mentors, teachers and peers would work towards strengthening relatedness and social competence with the teacher-and-peer-independent MT, this might ameliorate problems with peers, emotional problems and increase individual school self-concept.

\section{Acknowledgments}

The research reported in this paper was supported by a grant from The Volkswagen Foundation. The authors would like to thank the principals, teachers and students for their cooperation in making these studies possible.

\section{References}

Bergmann, L. R. (2001). A person approach in research on adolescence: Some methodological challenges. Journal of Adolescence Research, 16, 28-53. http://dx.doi.org/10.1177/0743558401161004

Birch, S., \& Ladd, G. (1997). The teacher- child relationship and children's early school adjustment. Journal of School Psychology, 35, 61-79. http://dx.doi.org/10.1016/S0022- 4405(96)00029-5

Black, K. A., \& McCartney, K. (1997). Adolescent females' security with parents predicts the quality of peer interactions. Social Development, 6, 91-110. http://dx.doi.org/10.1111/j.1467-9507.1997.tb00096.x 
Boulard, A., Quertemont, E., Gauthier, J.-M., \& Born, M. (2012). Social context in school: Its relation to adolescents' depressive mood. Journal of Adolescence, 35, 143-152. http://dx.doi.org/10.1016/j.adolescence.2011.04.002

Brown, T. A., \& Rosellini, A. J. (2011). The direct and interactive effects of neuroticism and life stress on the severity and longitudinal course of depressive symptoms. Journal of Abnormal Psychology, 120, 844-856. http://dx.doi.org/10.1037/a0023035

Bukowski, W. M., Simard, M., Dubois, M. E., \& Lopez, L. S. (2011). Representations, process, and development: A new look at friendship in early adolescence. In E. Amsel, \& J. G. Smetana (Eds.), Adolescent vulnerabilities and opportunities: Development and constructivist perspectives (pp. 159-181). New York: Cambridge University Press.

Busato, V. V., Prins, F. J., Elshout, J. J., \& Hamaker, C. (2000). A closer look at the inventory of learning styles (ILS). Pädagogische Studien, 77, 11-20.

Butkovic, A., Brkovic, I., \& Bratko, D. (2012). Predicting Well-Being from Personality in Adolescents and Older Adults. Journal of Happiness Studies, 13, 455-467. http://dx.doi.org/10.1007/s10902-011-9273-7

Cacioppo, J. T. (2002). Social neuroscience: Understanding the pieces fosters understanding the whole and vice versa. American Psychologist, 57, 819-831. http://dx.doi.org/10.1037/0003-066X.57.11.819

Caravita, S. C. S., Di Blasio, P., \& Salmivalli, C. (2009). Unique and interactive effects of empathy and social status on involvement in bullying. Social Development, 18, 140-163. http://dx.doi.org/10.1111/j.1467-9507.2008.00465.x

Chan, D. (2009). So why ask me? Are self-report data really that bad? In C. E. Lance, \& R. J. Vandenberg (Eds.), Statistical and methodological myths and urban legends (pp. 309-336). New York, NY: Routledge.

Cohen, S., \& Wills, T. A. (1985). Stress, Social Support, and the Buffering Hypothesis. Psychological Bulletin, 98, 310-357. http://dx.doi.org/10.1037/0033-2909.98.2.310

Comer, R. J. (2010). Abnormal Psychology (7th ed.). New York: Worth Publishers.

Crawford, M., \& Manassis, K. (2011). Anxiety, social skills, friendship quality and peer victimization: An integrated model. Journal of Anxiety Disorders, 25, 924-931. http://dx.doi.org/10.1016/j.janxdis.2011.05.005

Deci, E. L., \& Ryan, R. M. (1985). Intrinsic motivation and self-determination in human behavior. Plenum Press, NY: New York.

Decovic, M., \& Meeus, W. (1997). Peer relations in adolescence: Effects of parenting and adolescents' self-concept. Journal of Adolescence, 20, 163-176. http://dx.doi.org/10.1006/jado.1996.0074

Eccles, J. S., Midgley, C., Wigfield, A., Buchanan, C. M., Reuman, D., Flanagan, C., \& Mac Iver, D. (1993). Development During Adolescence: The Impact of Stage-Environment Fit on Young Adolescents' Experiences in Schools and in Families. American Psychologist, 48, 90-101. http://dx.doi.org/10.1037/0003-066X.48.2.90

Epkins, C. C., \& Heckler, D. R. (2011). Integrating Etiological Models of Social Anxiety and Depression in Youth: Evidence for a Cumulative Interpersonal Risk Model. Clinical Child and Family Psychological Review, 14, 329-376. http://dx.doi.org/10.1007/s10567-011-0101-8

Essau, C. A. (2007). Depression bei Kindern und Jugendlichen (2nd ed.). München, Germany: Ernst Reinhardt Verlag.

Flanagan, K. S., Erath, S. A., \& Bierman, K. L. (2008). Unique associations between peer relationships and social anxiety in early adolescence. Journal of Clinical Child and Adolescent Psychology, 37, 759-769. http://dx.doi.org/10.1080/15374410802359700.

Fröjd, S. A., Nissinen, E. S., Pelkonen, M. U. I., Marttunen, M. J., Koivisto, A.-M., \& Kaltiala-Heino, R. (2008). Depression and school performance in middle adolescent boys and girls. Journal of Adolescence, 31, 485-498. http://dx.doi.org/10.1016/j.adolescence.2007.08.006

Glogger, I., Schwonke, R., Holzäpfel, L., Nückles, M., \& Renkl, A. (2012). Learning strategies assessed by journal writing: Prediction of learning outcomes by quantity, quality, and combinations of learning strategies. Journal of Educational Psychology, 104, 452-468. http://dx.doi.org/10.1037/a0026683 
Goodman, A., Lamping, D. L., \& Ploubidis, G. B. (2010). When to use broader internalizing and externalizing subscales instead of the hypothesized Five Subscales on the Strengths and Difficulties Questionnaire (SDQ): Data from British parents, teachers and children. Journal of Abnormal Child Psychology, 38, 1179-1191. http://dx.doi.org/10.1007/s10802-010-9434-x

Goodman, R. (1997). The Strengths and Difficulties Questionnaire, A research note. Journal of Child Psychology and Psychiatry, 38, 581-586. http://dx.doi.org/10.1111/j.1469-7610.1997.tb01545.x

Gräfe, K., Zipfel, S., Herzog, W., \& Löwe, B. (2004). Screening psychischer Störungen mit dem "Gesundheitsfragebogen für Patienten (PHQ-D)". Ergebnisse der deutschen Validierungsstudie. Diagnostica, 50, 171-181. http://dx.doi.org/10.1026/0012-1924.50.4.171

Guay, F., Ratelle, C. F., Roy, A., \& Litalien, D. (2009). Academic self-concept, autonomous academic motivation, and academic achievement: Mediating and additive effects. Learning and Individual Differences, 20, 644-653. http://dx.doi.org/10.1016/j.lindif.2010.08.001

Guerin, D. W., Oliver, P. H., Gottfried, A. W., Gottfried, A. E., Reichard, R. J., \& Riggio, R. E. (2011). Childhood and adolescent antecedents of social skills and leadership potential in adulthood: Temperamental approach/withdrawal and extraversion. The Leadership Quarterly, 22, 482-494. http://dx.doi.org/10.1016/j.leaqua.2011.04.006

Hafen, C. A., Allen, J. P., Mikami, A. Y., Gregory, A., Hamre, B., \& Pianta, R. C. (2012). The Pivotal Role of Adolescent Autonomy in Secondary School Classrooms. Journal of Youth and Adolescence, 41, 245-255. http://dx.doi.org/10.1007/s10964-011-9739-2

Hamre, B. K., \& Pianta, R. C. (2006). Student-teacher relationships as a source of support and risk in schools. In G. G. Bear, \& K. M. Minke (Eds.), Children's needs III: Development, prevention, and intervention (pp. 59-71). Bethesda, ML: National Association of School Psychologists.

Hazell, P. (2002). Depression in Children. May go unnoticed and untreated. British Medical Journal, 325, 229-230. http://dx.doi.org/10.1136/bmj.325.7358.22

Hjern, A., Alfven, G., \& Gostberg, V. (2008). School stressors, psychological complaints and psychosomatic pain. Acta Paediatrica, 97, 112-117. http://dx.doi.org/10.1111/j.1651-2227.2007.00585

Hoferichter, F., \& Raufelder, D. (2014). Ein Modell inter-individueller Unterschiede sozio-motivationaler Beziehungen von Sekundarschülern mit ihren Peers und Lehrern. Schulpädagogik heute, 5(9).

Hu, L., \& Bentler, P. M. (1999). Cutoff criteria for fit indixes in covariance structure analysis: Conventional criteria versus new alternatives. Structural Equation Modeling, 6, 1-55. http://dx.doi.org/10.1080/10705519909540118

Jylha, P., \& Isometsa, E. (2006). The relationship of neuroticism and extraversion to symptoms of anxiety and depression in the general population. Depression and Anxiety, 23, 281-289. http://dx.doi.org/10.1002/da.20167

Kagitçibasi, C. (1996). The Autonomous-Relational Self: A new Synthesis. European Psychologist, 1, 180-186. http://dx.doi.org/10.1027/1016-9040.1.3.180.

Karvonen, S., Vikat, A., \& Rimpela, M. (2004). The role of school context in the increase in young people's health complaints. Journal of Adolescence, 28, 1-16. http://dx.doi.org/10.1016/j.adolescence.2004.05.006

Komarraju, M., \& Karau, S. J. (2005). The relationship between the big five personality traits and academic $\begin{array}{llll}\text { motivation. Personality and Individual Differences, } & \text { 39, }\end{array}$ http://dx.doi.org/10.1016/j.paid.2005.02.013

Kroenke, K., Spitzer, R., \& Williams, W. (2001). The PHQ-9: Validity of a brief depression severity measure. Journal of General Internal Medicine, 16, 606-613. http://dx.doi.org/10.1046/j.1525-1497.2001.016009606.x

Kupfer, J. (1987). Privacy, Autonomy, and Self-Concept. American Philosophical Quarterly, 24, 81-89.

Laidra, K., Pullmann, H., \& Allik, J. (2007). Personality and Intelligence as predictors of academic achievement: A cross-sectional study from elementary to secondary school. Personality and Individual Differences, 42, 441-451. http://dx.doi.org/10.1016/j.paid.2006.08.001

Lerner, R. M. (1986). Concepts and theories of human development (2nd ed.). New York, NY: Random House. 
Lerner, R. M. (1998). Theories of human development: Contemporary perspectives. In W. Damon (Series Ed.), \& R. M. Lerner (Eds.), Handbook of child psychology: Vol. 1 (5th Ed.): Theoretical models of human development (pp. 1-24). New York, NY: John Wiley \& Sons.

Luthar, S. S. (2003). The culture of affluence: Psychological costs of Material Wealth. Child Development, 74, 1581-1593. http://dx.doi.org/10.1046/j.1467-8624.2003.00625.x.

Lynch, M. F., La Guardia, J. G., \& Ryan, R. M. (2009). On being yourself in different cultures: Ideal and actual self-concept, autonomy support, and well-being in China, Russia, and the United States. Journal of Positive Psychology, 4, 290-304. http://dx.doi.org/10.1080/17439760902933765

MacKinnon, D. P. (2008). Introduction to statistical mediation analysis. Mahwah, NJ: Erlbaum.

Magnusson, D. (2003). The person approach: Concepts, measurement models, and research strategy. In S. C. Peck, \& R. W. Roeser (Eds.), New directions for Child and Adolescent development. Person-centered approaches to studying development in context (No. 101, pp. 3-23). San Francisco, CA: Jossey-Bass.

Muthén, B. O., \& Muthén, L. K. (2000). Integrating person-centered and variable-centered analyses: Growth mixture modeling with latent trajectory classes. Alcoholism: Clinical and Experimental Research, 24, 882-891. http://dx.doi.org/10.1111/j.1530-0277.2000.tb02070.x

Mynard, H., \& Joseph, S. (1997). Bully/ victim problems and their association with Eysenck's personality dimensions in 8 to 13 year-olds. British Journal of Educational Psychology, 67, 51-54. http://dx.doi.org/10.1111/j.2044-8279.1997.tb01226.x

Petermann, F. (2005). Zur Epidemiologie psychischer Störungen im Kindes-und Jugendalter-Eine Bestandsaufnahme. Kindheit und Entwicklung, 14, 48-57. http://dx.doi.org/10.1026/0942-5403.14.1.48

Phillips, B. N. (1993). Educational and psychological perspectives on stress in students, teachers, and parents. Brandon, VT: Clinical Psychology Publishing Company.

Preacher, K. J., \& Hayes, A. F. (2008). Asymptotic and resampling strategies for assessing and comparing indirect effects in multiple mediator models. Behavior Research Methods, 40, 879-891. http://dx.doi.org/10.3758/BRM.40.3.879

Prenzel, M., Kristen, A., Dengler, P., Ettle, R., \& Beer, T. (1996). Selbstbestimmtes motiviertes und interessiertes Lernen in der kaufmännischen Erstausbildung. Zeitschrift für Berufs-und Wirtschaftspädagogik, 13, 108-127.

Raufelder, D., Drury, K., Jagenow, D., Hoferichter, F., \& Bukowski, W. (2013). Development and Validation of the Relationship and Motivation (REMO) scales to assess students' perceptions of peers and teachers as motivators in adolescence. Learning and Individual Differences, 23, 182-189. http://dx.doi.org/10.1016/j.lindif.2013.01.001

Raufelder, D., Jagenow, D., Drury, K., \& Hoferichter, F. (2013). Social Relationships and Motivation in Secondary School: 4 different motivation types. Learning and Individual Differences, 24, 89-95. http://dx.doi.org/10.1016/j.lindif.2012.12.002

Riemann, R., \& Allgöwer, A. (1993). Eine deutschsprachige Fassung des "Interpersonal Competence Questionnaire" (ICQ). Zeitschrift für differentielle und diagnostische Psychologie, 14, 153-163.

Roffey, S. (2012). Developing positive relationships in schools. In S. Roffey (Ed.), Positive relationships: Evidence based practice across the world (pp. 145-162). New York, NY: Springer.

Rubin, K. H., Dwyer, K. M., Booth-LaForce, C., Kim, A. H., Burgess, K. B., \& Rose-Krasnor, L. (2004). Attachment, friendship, and psychosocial functioning in early adolescence. Journal of Early Adolescence, 24, 326-356. http://dx.doi.org/10.1177/ 0272431604268530

Ryan-Wenger, N., Sharrer, V., \& Campbell, K. (2005). Changes in children's stressors over the past 30 years. Pediatric Nursing, 31, 282-291.

Schneider, R. J., Ackerman, P. L., \& Kanfer, R. (1996). To "act wisely in human relations": Exploring the dimensions of social competence. Personality and individual differences, 21, 469-481. http://dx.doi.org/10.1016/0191-8869(96)00084-0

Schöne, C., Dickhäuser, O., Spinath, B., \& Stiensmeier-Pelster, J. (2002). Skalen zur Erfassung des schulischen Selbstkonzeptes. SESSKO. Göttingen, Germany: Hogrefe. 
Spector, P. E. (2006). Method variance in organizational research: Truth or urban legend? Organizationl Research Methods, 9, 221-232. http://dx.doi.org/10.1177/1094428105284955

Swanberg, A. B., \& Martinsen, O. L. (2010). Personality, approaches to learning and achievement. Educational Psychology, 30, 75-88. http://dx.doi.org/10.1080/01443410903410474

Szirmák, Z. (2005). The Big Five Model of Personality and Primary Prevention in Adolescence. Retrieved, January 16, 2012, from Freie Universität Berlin. http://dx.doi.org/10.1177/1073191107313761

Thorndike, E. L. (1920). Intelligence and its uses. Harper's Magazine, 140, 227-235.

Tyssen, R., Dolatowski, F. C., Røvik, J. O., Thorkildsen, R. F., Ekeberg, Ø., Hem, E., ... Vaglum, P. (2007). Personality traits and types predict medical school stress: A six-year longitudinal and nationwide study. Medical Education, 41, 781-787. http://dx.doi.org/10.1111/j.1365-2923.2007.02802.x

Valdez, C. R., Lambert, S. F., \& Ialongo, N. S. (2011). Identifying Patterns of Early Risk for Mental Health and Academic Problems in Adolescence: A Longitudinal Study of Urban Youth. Child Psychiatry and Human Development, 42, 521-538. http://dx.doi.org/10.1007/s10578-011-0230-9

Valkenburg, P. M., \& Peter, J. (2008). Adolescents' Identity Experiments on the internet: Consequences for Social Competence and Self-Concept Unity. Communication Research, 35, 208-231. http://dx.doi.org/10.1177/0093650207313164

Véronneau, M.-H., Vitaro, F., Brendgen, M., Dishion, T. J., \& Tremblay, R. E. (2010). Transactional Analysis of the Reciprocal Links Between Peer Experiences and Academic Achievement From Middle Childhood to Early Adolescence. Developmental Psychology, 46, 773-790. http://dx.doi.org/10.1037/a0019816

Von Eye, A., \& Bogat, G. A. (2006). Person orientation-Concepts, results and development. Merrill Palmer Quarterly, 52, 390-420.

Wehmeyer, M. L., \& Schalock, R. L. (2001). Self-determination and quality of life: Implications for special education services and supports. Focus on Exceptional Children, 33, 1-16.

Wentzel, K. R. (1991). Relations between social competence and academic achievement in early adolescence. Child Development, 62, 1066-1078. http://dx.doi.org/10.1111/j.1467-8624.1991.tb01589.x

Wentzel, K. R., \& Asher, S. R. (1995). Academic lives of neglected, rejected, popular, and controversial children. Child Development, 66, 754-763. http://dx.doi.org/10.1111/j.1467-8624.1995.tb00903.x

Wentzel, K. R. (1998). Social relationships and motivation in middle school: The role of parents, teachers, and peers. Journal of Educational Psychology, 90, 202-209. http://dx.doi.org/10.1037/0022-0663.90.2.202

Wentzel, K. R. (2009a). Peer relationships and motivation at school. In K. Rubin, W. M. Bukowski, \& B. Laursen (Eds.), Hanbook of peer interactions, relationships, and groups (pp. 531-547). New York, NY: Guilford.

Wentzel, K. R. (2009b). Students' relationships with teachers as motivational context. In K. R. Wentzel, \& A. Wigfield (Eds.), Handbook of motivation at school (pp. 301-322). New York, NY: Routledge.

Wentzel, K. R., Battle, A., Russell, S. L., \& Looney, L. B. (2010). Social supports from teachers and peers as predictors of academic and social motivation. Contemporary Educational Psychology, 35, 193-202. http://dx.doi.org/10.1016/j.cedpsych.2010.03.002

Wigfield, A., \& Eccles, J. S. (2001). Development of achievement motivation. San Diego, CA: Academic Press.

\section{Copyrights}

Copyright for this article is retained by the author(s), with first publication rights granted to the journal.

This is an open-access article distributed under the terms and conditions of the Creative Commons Attribution license (http://creativecommons.org/licenses/by/3.0/). 